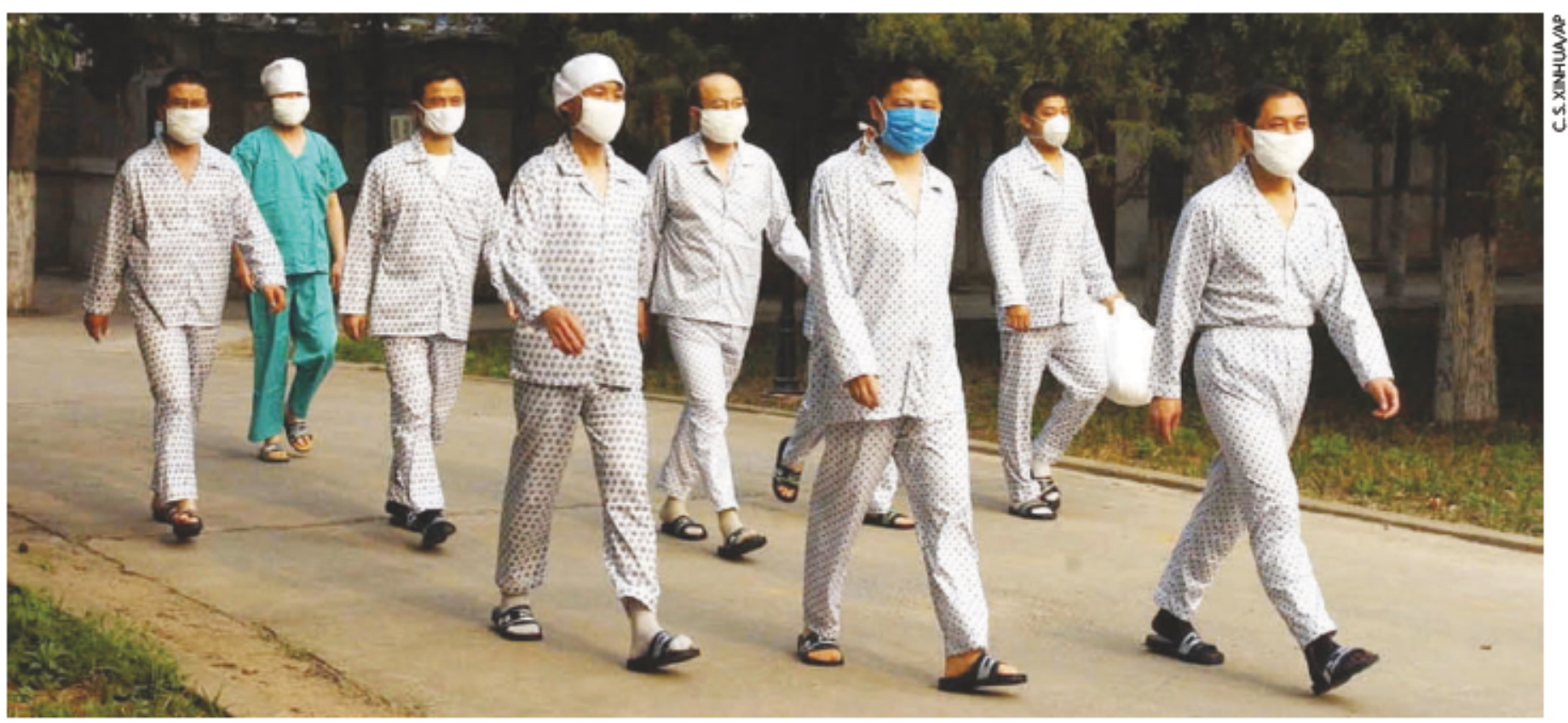

\title{
Is China prepared for microbial threats?
}

\author{
There is no bigger acute microbial threat to China, and to the rest of the world, than an influenza pandemic, and \\ no better time to prepare for this eventuality than now. David $\mathrm{Ho}$ asks what more China could be doing.
}

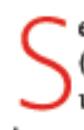
evere acute respiratory syndrome (SARS) was unquestionably a loud wakeup call for China. The outbreak of this transmissible disease caught the health authorities unprepared. The country's disease-surveillance system was slow to recognize and report the new syndrome, and the magnitude of the threat was not, at first, fully appreciated. The problem was exacerbated because health officials did not, initially, handle the burgeoning epidemic with the transparency that the crisis required. A chance to nip the outbreak in the bud was lost, and the consequences were devastating for both China and the rest of the world.

SARS spread rapidly in early 2003 from the southern province of Guangdong to other parts of the country, most notably Beijing and Hong Kong. It also spread by air travel, quickly surfacing in places such as Vietnam, Singapore, Taiwan and Canada. SARS was recognized as a new disease by medical professionals in Hong Kong and international health officials working in Vietnam. With unprecedented speed, the causative agent was isolated and identified as a previously unknown form of coronavirus.

Fortunately, China took stock of the situation and by April 2003 had made a course correction. In the end, the political will to end the epidemic was impressive, and the new openness in addressing the disease was refreshing. By launching a concerted publichealth effort that included draconian measures such as quarantine, China brought SARS under control faster than anyone could have predicted - the outbreak was over by that summer. The success was not only commendable, but a testament to Chinese resourcefulness once a clear path is apparent. But China - and the world - paid a high price: cities were paralysed for months, billions of dollars were lost, more than 8,000 people were infected, and about 800 lives taken.

\section{High alert}

China is now confident that it could handle the re-emergence of SARS. But is it sufficiently prepared for other major microbial threats that will emerge or expand in the near future? The Chinese epidemic surveillance system seems appropriate on paper, with its extensive network of disease centres at the national, provincial and local levels. But many of the deficiencies highlighted during the SARS outbreak remain.

Despite a significant infusion of funds in 2003, the disease-surveillance system is still grossly underfunded, and consequently lacks sufficient human resources and technical capacity. Sufficient resources must be allocated to train enough professionals to safeguard against epidemic diseases. Currently, too few of China's health workers have been properly trained to carry out the task. It is imperative that a cadre of medical and publichealth officers are formally trained in special programmes, such as those at the Epidemiologic Intelligence Service of the US Centers for Disease Control or at the World Health
Organization's office in Lyon. Trained individuals could, in turn, mentor others and so build the critical mass of professionals necessary to rejuvenate the Chinese disease-surveillance network.

China's disease-alert system must also be upgraded. The country's prowess in information technology should be applied to create a rapid automated mechanism to report clusters of unusual syndromes or specific infections from its vast network of clinics and hospitals. Such a system should also be alerted when certain pathogenic microbes are identified in the clinical laboratories. The ProMED-mail list for tracking infectious diseases worldwide could serve as a model.

Once the information is received centrally at the Chinese Centre for Disease Control, it must be processed by disease experts who can respond in a thorough and expeditious manner. Anything of concern should be rapidly disseminated to physicians and public-health specialists so that they are on the alert for similar illnesses or infections. When appropriate, such warnings should also go to government leaders, the media and international health agencies. To avert or blunt another catastrophe like SARS, China urgently needs a more efficient and transparent instrument to spot early disease outbreaks and to propagate the warning.

Two fundamental problems must also be addressed to improve China's preparedness for significant microbial threats. First, China must make microbial threats to health a top 
priority in its national research agenda. Greater financial resources should be given to microbiologists in academic institutions and government research units. This sort of commitment will undoubtedly result in a higher level of technical competence, which will be valuable during any serious microbial outbreak. A larger critical mass of experts could provide strategic advice and diagnostic tools to fight an epidemic. It could also help develop the therapies and vaccines needed to end the threat. Second, healthcare infrastructure has suffered years of neglect. Among the adverse consequences is a relatively low level of proficiency among physicians in China. This deficit will in turn allow certain epidemics to escape early detection, because these doctors are the first line of defence.

\section{Latest threats}

There is no bigger acute microbial threat to China than the next influenza pandemic. The world suffered greatly from three such pandemics in the twentieth century, including the Spanish flu of 1918-19 that killed more than 20 million people. Another flu pandemic is not only inevitable, but overdue. There is nobetter time to prepare for this eventuality than now, as an aggressive influenza virus, $\mathrm{H} 5 \mathrm{~N} 1$, has been continuously plaguing avian species over the past two years in about a dozen Asian countries, including China.

This viral variant is deadly in chickens and ducks; it also killed about 40 humans who were infected through direct contact with avian species. Fortunately, this virus has yet to acquire the ability to transmit from person to person (with a few exceptions); otherwise, we would be facing a pandemic already. Nevertheless, the current situation is of grave concern. Chinese scientists have already isolated H5N1 from nasal secretions of pigs, a species that can replicate both avian and human influenza viruses. It is only a matter of time before $\mathrm{H} 5 \mathrm{~N} 1$ and a human influenza virus mix and 'reassort' in porcine hosts to yield a new virulent strain that is capable of human-to-human transmission. It seems as though all the essential elements are now in place to produce a new influenza pandemic, most likely emerging from southeast Asia or China.

The world, China included, must respond as if the next pandemic is imminent. In August 2004, the US government released its national pandemic preparedness plan, broadly outlining the actions that will be taken. Various deficiencies were emphasized, including difficulties in implementing certain public-health measures such as quarantine. Despite its technical superiority, the United States faces a major shortfall in manufacturing the right vaccine and in stockpiling anti-influenza drugs. An estimated 89,000 to 207,000 Americans will die in the next pandemic. What would the death toll be in China?

China's recent SARS-fighting experience will give its pandemic response an edge. But this advantage will be offset by a number of factors: China is likely to be hit first or early by the pandemic, its disease-surveillance system and overall healthcare infrastructure are inadequate; the health authorities have yet to come up with a detailed strategic preparedness plan; and it has limited technical resources to produce enough vaccines and drugs to combat the pandemic. There is little doubt that China will be in deep trouble if the flu pandemic were to strike in the next few years. It has a moral obligation to its own people, and to the world, to rectify the situation as soon as possible.

In the aftermath of SARS, China saw many of its health challenges in a fresh light. Prominent among them was another

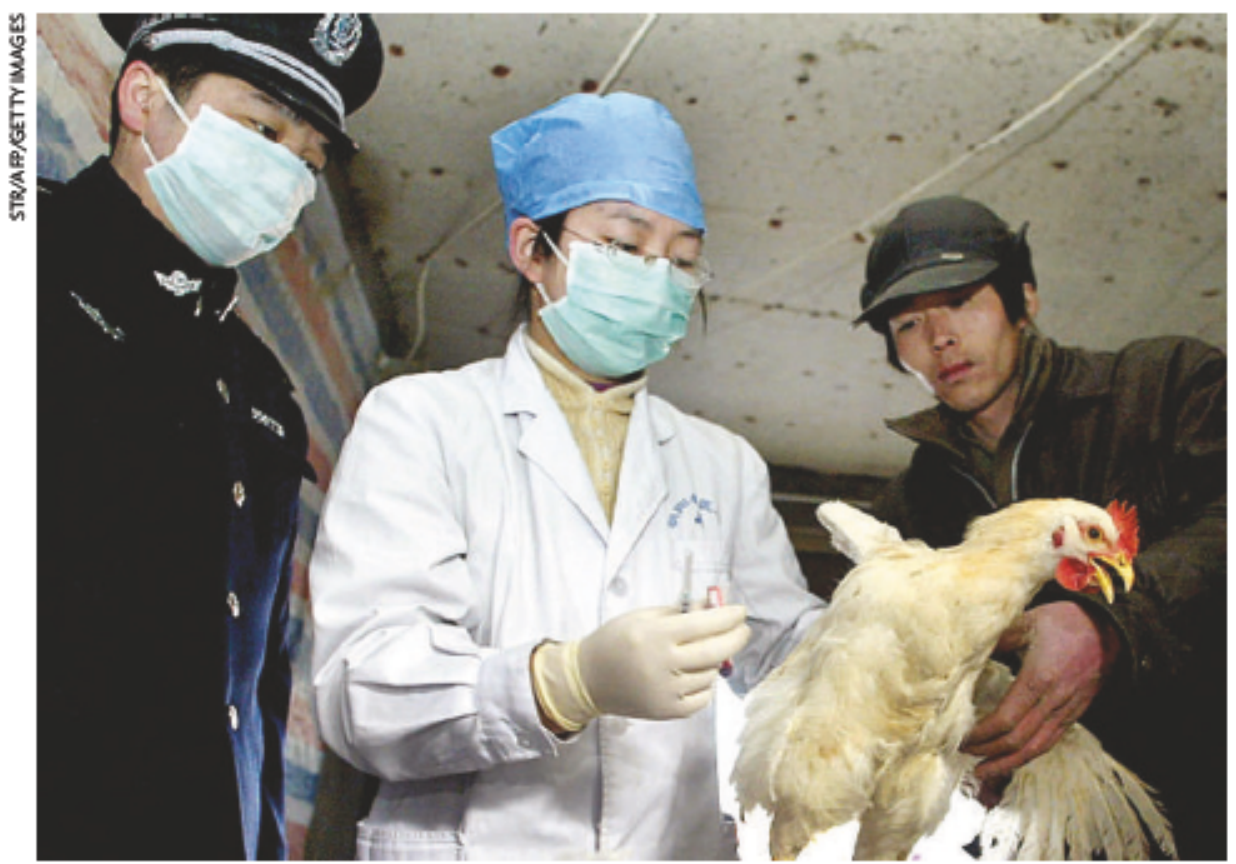

The next threat: a chicken is tested for avian flu at a poultry farmin Beijing.

epidemic transmissible disease. HIV/AIDS reached China in the mid-1980s, but the significant spread began in 1989 among injecting drug users in the southwest province of Yunnan. Following the tracks of heroin, this deadly virus spread to the adjacent provinces of Guangxi and Sichuan, and to the northwest autonomous region of Xinjiang. In addition, a separate HIV/AIDS epidemic exploded in the 1990s in Henan and neighbouring provinces, where unsanitary blood collection led to the infection of countless poor farmers.

Today, China has nearly 1 million individuals who are HIV-positive. But nine out of ten of them do not know that they are infected. About half the Chinese population knows little or nothing about HIV. The Joint United Nations Programme on HIV/AIDS, UNAIDS, has highlighted this epidemic as 'China's titanic peril, suggesting that 10 million people could become infected by the end of this decade. And yet until relatively recently, the Chinese response to the issue was somewhat muted.

The experience of the SARS outbreak has helped to change that. Slowly but surely, China is adopting its SARS-fighting attitude to combat HIV. There is now a centrally coordinated AIDS office with sufficient political will and clout to address the epidemic.

Although much could still be improved, China's recent AIDS policies are moving in the right direction. For example, the government has begun to offer free HIV testing and antiretroviral therapy, and has launched largescale surveillance in several provinces. Prevention programmes such as condom promotion and distribution, methadone maintenance, and even needle and syringe exchanges are emerging. Similar forwardlooking approaches should be applied to a flu pandemic preparedness plan.

\section{Prospects}

In the past two decades, the world has been awed by China's single-minded determination to become a nation that is technologically advanced and economically strong. Its economic growth during this period has been unprecedented. Its booming manufacturing capability is beginning to lift the country out of the developing world. It is high time for China to place greater importance on one of the hidden costs of its economic rise: the health of its population. Ultimately, this vital priority will only be attained if the national epidemic surveillance system is significantly upgraded. More emerging infections are inevitable, as the past century attests. China must be better equipped to deal with potential calamities posed by serious microbial threats. After all, there will be no prosperity if there is no health.

David $\mathrm{Ho}$ is at the Aaron Diamond AIDS Research Center, Rockefeller University, 455 First Avenue, New York, New York 10016, USA. 